Int. J. Electrochem. Sci., 14 (2019) 4933 - 4945

International Journal of

ELECTROCHEMICAL

SCIENCE

www.electrochemsci.org

Short Communication

\title{
All-solid-state $\mathrm{Ca}^{2+}$ Ion-selective Electrode with Black Phosphorus and Reduced Graphene Oxide as the Mediator Layer
}

Qingliang Yang ${ }^{1}$, Miao Zhang ${ }^{1,2 *}$, Chen Ming ${ }^{1}$, Gang Liu ${ }^{1,2}$, Maohua Wang ${ }^{1,2}$

${ }^{1}$ Key Laboratory on Modern Precision Agriculture System Integration Research of Ministry of Education, China Agricultural University, Beijing, China 100083.

${ }^{2}$ Key Lab of Agricultural Information Acquisition Technology, China Agricultural University, Beijing, China 100083.

"E-mail: zhangmiao@ cau.edu.cn

doi: $10.20964 / 2019.06 .45$

Received: 29 January 2019 / Accepted: 23 March 2019 / Published: 10 May 2019

An all-solid-state $\mathrm{Ca}^{2+}$ ion-selective electrode $\left(\mathrm{Ca}^{2+}-\right.$ ISE), employing a composite mediator layer of reduced graphene oxide (RGO)-coated black phosphorus (BP), was developed and analyzed. The morphological characteristics of the prepared $\mathrm{Ca}^{2+}$-ISE were compared with those of other $\mathrm{Ca}^{2+}$-ISEs with solid-contact monolayers of RGO or BP. The potentiometric performance of the designed ISE was systematically verified. An ideal Nernstian response was observed with a stable linear range from $1.0 \times 10^{-6}-1.0 \times 10^{-1} \mathrm{M}$, a response slope of $28.3 \mathrm{mV} /$ decade, and a limit of detection of $7.2 \times 10^{-6} \mathrm{M}$. Due to the outstanding hydrophobic performance of the RGO-coated mediator film, the potential drift of the $\mathrm{Ca}^{2+}$-ISE decreased to $0.01 \mathrm{mV} \mathrm{s}^{-1}$. In addition, the ISE demonstrated good stability with a negligible potential variation of less than $2.86 \mu \mathrm{V} \mathrm{s}^{-1}$ when exposed to a variety of interferences, such as ambient light and gases. The sensitivity was maintained at a satisfactory level after continuous use over 10 days. Real lettuce nutrient solutions were applied to validate the feasible application of this ISE. Promising capabilities were found with detection recovery rates ranging from $87 \%$ to $112 \%$.

Keywords: Calcium; All-solid-state ion-selective electrode; Black phosphorus; Reduced graphene oxide; Composite mediator layer.

\section{FULL TEXT}

(C) 2019 The Authors. Published by ESG (www.electrochemsci.org). This article is an open access article distributed under the terms and conditions of the Creative Commons Attribution license (http://creativecommons.org/licenses/by/4.0/). 